\title{
Zum 70. Geburtstag von A. von Hippel.
}

Arthur v. Hippel, der Professor ord. der Augenheilkunde an der Göttinger Universität, feierte am 24. Oltohar seinen 70. Geburtstag, wozu ihm seine Freunde, Kollegen und Schüler ihre herzlichsten Glückwünsche darbracht»n. A. v. Hippel wurde am 24. Oktobər 1841 zu Domäne Fischhausen in Ostpreußen geboren, studierte in Königsberg, Würzburg, Berlin und promovierte 1864. Nach tinigen Studienreisen begann er bald, sicls besonders der Augenheilkunde zuzuneigen. Er hatte zwei vorzügliche Loshrmeister, die ihn in dieses Fach einführten, v. Arlt in

Wien und J. Jacob. son in Königsberg. Aber seine Lohrer sollten auch bald Freude an ihrem Schüler er. leben. 1868 habilitierte er sich in Königsberg, 1874 wurde er Extraordinarius und 1879 Ordinarius in Gießen. Als Nachfolger J aco b sons kam er 1890 nach Königsberg, dann 1892 an Stelle von Alfred Graefe nach Halle. Jetzt wirkt er, gleich tüchtig und beliebt als Lshrer wie als Arzt, gleich tätig und fleißig als Forscher, wie als Publizist in Göttingen.

Seiner energischen Natur ist es auch gelungen, einer langen Krankheit, die vor wenigen Jahren übar ihn kam, Herr zu werden, sodaß wir unseren verehrten Kollegen heute wieder in voller geistiger und körperlicher Frische, in reger und ausgedehnter Tätigkeit sehen und begrüßen können. Möge es noch lange so bleiben, das wünschen wir ihm und uns. R. Greeff (Berlin). 